\title{
Editorial
}

\section{Insect exocrine glands}

Johan Billen, University of Leuven, Zoological Institute, Naamsestraat 59, box 2466, B-3000 Leuven, Belgium; e-mail: johan.billen@bio.kuleuven.be

Jan Šobotník, Czech University of Life Sciences, Faculty of Forestry and Wood Sciences, 16521 Prague 6, Czech Republic; e-mail: sobotnik@fld.czu.cz

'Describe the differences between endocrine and exocrine glands', it sounds a typical exam question from a general biology course during our time at high school. Because of their secretory products being released to the outside world, exocrine glands definitely add flavour to our lives. Everybody is familiar with their secretions, from the salty and perhaps unpleasantly smelling secretions from mammalian sweat glands to the sweet exudates of the honey glands used by some caterpillars to attract ants, from the most painful venoms of bullet ants and scorpions to the precious wax that honeybees use to make their nest combs. Besides these functions, exocrine glands are especially known for the elaboration of a broad spectrum of pheromonal substances, and can also be involved in the production of antibiotics, lubricants, and digestive enzymes.

Modern research in insect exocrinology started with the classical works of Charles Janet, who introduced a histological approach to the insect world (Billen and Wilson 2007). The French school of insect anatomy remained strong since then, and the commonly used classification of insect exocrine glands generally follows the pioneer paper of Charles Noirot and André Quennedey (1974). These authors were leading termite researchers using their extraordinary knowledge on termite glands to understand related phenomena, such as foraging and reproductive behaviour. They distinguish between class 1 with secretory cells adjoining directly to the cuticle, and class 3 with bicellular units made up of a large secretory cell and its accompanying duct cell that carries the secretion to the exterior (Fig. 1). The original classification included also class 2 secretory cells, but these are very rare and are only found in sternal and tergal glands of a cockroach and many termites (and also in the novel nasus gland described in this issue!). This classification became universally used, with the rather strange consequence that the vast majority of insect glands is illogically made up of class 1 and class 3 cells. In a follow-up paper, the uncommon class 2 cells were re-considered as oenocyte homologues (Noirot and Quennedey 1991). Irrespectively of these objections, their 1974 pioneer paper is a cornerstone of modern works dealing with insect exocrine glands, as is also obvious in the 
majority of the papers in this special issue. This paper already received 545 citations at Web of Science and 588 at Google Scholar (both on 24 Aug 2015), so one can easily say that all researchers working on insect glands consider this work truly fundamental.

Exocrine glands are organs of cardinal importance in all insects. The more common ones include mandibular and labial glands of cephalic origin (although the latter are often pushed backwards into thorax or abdomen), dorso- or ventro-abdominal and pygidial glands, and silk glands of manifold embryogenetic origins. Gland diversity obviously peaks in social insects, revealing an unprecedented variety that reflects the complexity of social life. All social insects live in a tight network world of pheromonal signals that can reach a high complexity when various glands contribute to the elaboration of multicomponent chemical blends. The overall number of exocrine glands described so far for all social insects is 149 , and this impressive figure will for sure continue rising. Looking more in detail, 84 different glands are known in ants, 53 in bees and bumblebees, 49 in wasps and 20 in termites (the overall total of 149 obviously is not a mere summing up of the various groups, as several glands occur in more than one group - labial glands for instance are found in all groups; venom and Dufour glands occur in all Hymenopteran species). These overall figures for the various groups include the 11 novel glands (10 in wasps and 1 in termites) that are described in this issue.

This special issue of Arthropod Structure and Development brings nine novel reports on exocrine glands in diverse insect taxa, which are scattered all over the body, from the very anterior head to the very posterior abdomen. The first contribution by Šobotník et al. describes a novel organ in termites, the nasus gland, representing the very first cephalic gland consisting of all three classes of secretory cells as defined by Noirot and Quennedey (1974). Jia and Liang provide interesting observations on highly modified class 3 secretory cells occurring among ommatidia of the compound eyes in water bugs. Penagos-Arévalo et al. performed a comparative analysis of cephalic exocrine organs in a representative set of Neotropical Polistinae wasps, and found an enormous diversity of these organs, of which most are described for the first time. Costa-Leonardo et al. conducted a detailed study of tarsal glands in termites, for which no cytological details were previously known. Nijs and Billen undertook an in-depth study of the legs in the common wasp Vespula vulgaris that revealed an astonishing diversity of exocrine organs, of which most had not been observed so far. Vieira et al. studied the metapleural gland in two species of leaf-cutting ants, and report on the relationships between pathogen load and gland complexity that allows to overcome high risks of nesting in pathogen-rich soils. Krueger et al. provide an interesting comparative study of male sternal glands in three thrips species. Di Giulio et al. report on the comparative morphology of the famous pygidial defensive glands in eight species of bombardier beetles. Last but not least, Gnatzy et al. bring a multidisciplinary study involving structural and ultrastructural observations, as well as biochemical and analytical approaches to understand the function of the venom and Dufour's glands in a representative of Sphecidae parasitoid wasps. We are very proud to bring all these pivotal observations together in 
this special issue. We are confident this issue illustrates that insect anatomy and morphology is an exciting field of research, which provides innumerable examples to stimulate man's curiosity. We kindly invite our readers to sink in the great deep sea of fascinating microstructures!

Our acknowledgements go to the journal's Editors Alexander Steinbrecht and Nick Strausfeld for inviting us to be Guest Editors of this special issue. Our very special thanks of course go to the authors who contributed to this issue, and to the several reviewers who kindly assisted during the evaluation process.

\section{References}

Billen J., Wilson E.O. 2007: Social insect histology from the nineteenth century: The magnificent pioneer sections of Charles Janet. Arthropod Structure \& Development 37, 163-167.

Noirot C., Quennedey A. 1974: Fine structure of insect epidermal glands. Annual Review of Entomology 19, 61-80.

Noirot C., Quennedey A. 1991: Glands, gland cells, glandular units: some comments on terminology and classification. Annales de la Société entomologique de France (Nouvelle Série) 27, 123-128.

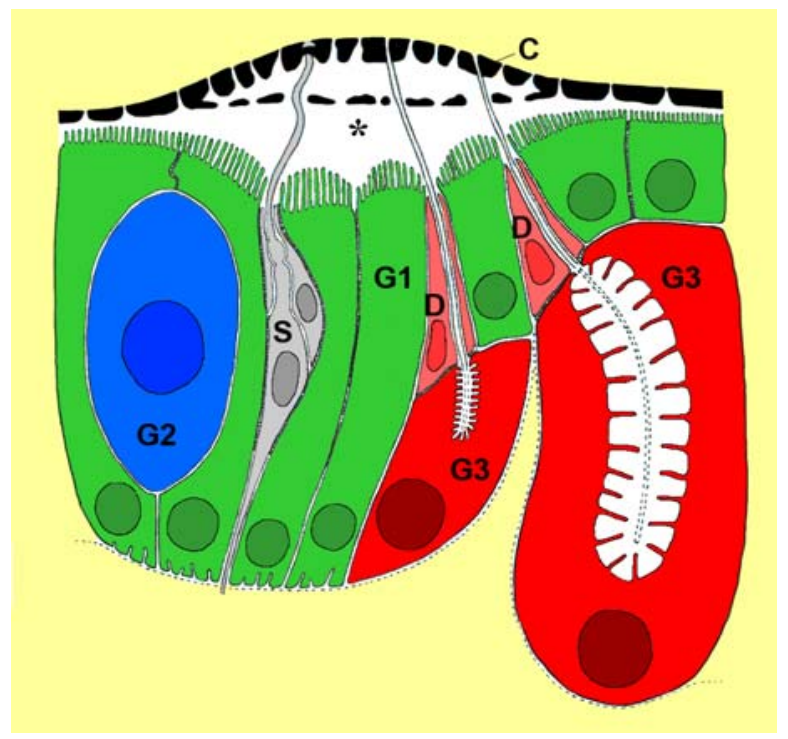

Fig. 1. Noirot and Quennedey's original classification of insect exocrine glands, based on a rhinotermitid sternal gland. The asterisk indicates a subcuticular space. Abbreviations: C, cuticle; D, duct cells; G1, secretory cells class $1 ; \mathrm{G} 2$, secretory cells class 2; G3, secretory cells class 3; S, campaniform sensilla (modified after Noirot and Quennedey 1974). 